\title{
Editorial: Governing Carbon Dioxide Removal
}

\author{
Rob Bellamy ${ }^{1,2 *}$, Oliver Geden ${ }^{2,3}$, Mathias Fridahl ${ }^{4,5}$, Emily Cox ${ }^{6}$ and James Palmer ${ }^{2,7}$ \\ ${ }^{1}$ Department of Geography, University of Manchester, Manchester, United Kingdom, ${ }^{2}$ Institute for Science, Innovation and \\ Society, University of Oxford, Oxford, United Kingdom, ${ }^{3}$ German Institute for International and Security Affairs, Berlin, \\ Germany, ${ }^{4}$ Department of Thematic Studies - Environmental Change, Linköping University, Linköping, Sweden, ${ }^{5}$ Centre for \\ Climate Science and Policy Research, Linköping University, Linköping, Sweden, ${ }^{6}$ School of Psychology, Cardiff University, \\ Cardiff, United Kingdom, ${ }^{7}$ School of Geographical Sciences, University of Bristol, Bristol, United Kingdom
}

Keywords: climate policy, governance, carbon dioxide removal, greenhouse gas removal, negative emissions

\section{Editorial on the Research Topic}

Governing Carbon Dioxide Removal

\section{INTRODUCTION}

Carbon dioxide removal (CDR), also known as negative emissions, greenhouse gas removal, or simply carbon removal, is in need of effective governance. If governments are to deliver on the growing number of pledges to meet "net zero" and "net-negative" emissions targets, and if the world is to successfully limit global warming to "well-below $2{ }^{\circ} \mathrm{C}$ " compared to pre-industrial levels, then

\section{OPEN ACCESS}

Edited and reviewed by: Phil Renforth,

Heriot-Watt University,

United Kingdom

${ }^{*}$ Correspondence: Rob Bellamy rob.bellamy@manchester.ac.uk

Specialty section:

This article was submitted to Negative Emission Technologies,

a section of the journal

Frontiers in Climate

Received: 16 November 2021 Accepted: 17 November 2021 Published: 08 December 2021

Citation:

Bellamy R, Geden O, Fridahl M, Cox E and Palmer J (2021) Editorial: Governing Carbon Dioxide Removal.

Front. Clim. 3:816346.

doi: 10.3389/fclim.2021.816346 carbon dioxide $\left(\mathrm{CO}_{2}\right)$ will need to be removed from the atmosphere. This is because, at the very least, residual greenhouse gas emissions from hard-to-transition sectors like agriculture will need to be compensated for. Furthermore, if the world were to overshoot $1.5^{\circ}, \mathrm{CO}_{2}$ concentrations will need to be brought back down. The central questions for CDR governance therefore no longer concern whether CDR should be pursued, but how; which CDR methods should be pursued, to what extent, when, where, and by whom (Bellamy and Geden, 2019). Despite this, the governance frameworks and democratic processes that will be needed to responsibly incentivize, develop, and sustain CDR remain largely neglected not just by policymakers, but also by much of the academic research community as well.

Spurring demand for CDR not just from multiple policy angles, but also multiple policy scales, will require an approach that minimizes negative trade-offs and identifies potential co-benefits (Cox and Edwards, 2019). Yet uncertainties around CDR effectiveness, technical efficiency, scale, risks, and interactions with other policy objectives-both within and beyond the realm of climate governance-all demand careful consideration (Fridahl et al., 2020). Moreover, effective CDR governance must also contend with conflicting interests and account for diverse and geographically varying societal values and knowledges in relation to technology appraisal and selection, policy instrument choice, and guiding principles (Bellamy, 2018; Bellamy et al., 2021). This Research Topic seeks to address such critical questions around CDR governance as it emerges: how is CDR framed and what are the governance implications? How can we account for societal values and knowledges in CDR governance? How do existing governance regimes relate to CDR and how might they be reformed? What new governance designs are needed? Are existing institutions and systems suitable for governing CDR? 


\section{FRAMING GOVERNANCE}

Otto et al. undertake a secondary analysis of interviews with German environmental NGO representatives to identify CDR narratives. They find two stories that reflect dominant climate policy discourses around ecological modernization and civic environmentalism: that $\mathrm{CDR}$ is either a necessity or a risk to mitigation, respectively. Turning to the envisaged role of CDR in different countries' long-term low emission development strategies, Buylova et al. find that national plans echo such discourses. They identify three possible visions for CDR: as a panacea that risks deterring mitigation, as a necessary fallback in case mitigation is not enough, and as a chimera in which CDR is illusory due to a lack of specific targets and plans. Asayama argues that the apparent paradox of CDR being essential but also a potential distraction has less to do with CDR itself than with the difficulties of escaping carbon lock-in. To better situate CDR in the challenge of rapid decarbonization, he argues, we should be asking how it can be used in alignment with a managed decline in fossil fuel production.

Boettcher undertakes a sociology-of-knowledge discourse analysis of interviews with UK stakeholders working at the industry-policy interface, to explore the competing forms of knowledge shaping assumptions about appropriate governance instruments for CDR. She reveals three dominant knowledge types: political-realist, utilitarian-economic, and discourseethical; and highlights the need for further "opening up" of discursive diversity in the development of CDR governance. Castree draws attention to how metaphors in particular will help to govern future action on CDR by framing present-day understandings of a world to come, and in turn how we might responsibly steer the use of metaphors to avoid depoliticization, polarization, or oversimplification. He argues for a "post normal" discourse on CDR, where high-stakes decisions made in the context of epistemic uncertainty are informed by clear reasoning among divergent actors and their values.

Boettcher et al. explore the increasing attention paid to marine CDR, and in particular how developments within four intertwined knowledge systems and governance sectors-namely modeling pathways, climate policy, innovation, and international legal frameworks-could result in different futures. In one future, hype around marine CDR delays decarbonization, while in another, reforms to research and governance practices seek co-benefits between ocean protection, economy, and climate. Lezaun et al. review how the more specific climate policy of a 2050 net zero target in the UK is forcing the integration of two disparate policy domains-forestry and geoengineeringand a more explicit articulation of the role CDR is expected to play. Net zero, they argue, provides an opportunity to bring transparency and accountability to underlying tensions, such as around "natural" and "engineered" CDR, by making explicit the role of CDR and subjecting them to public debate.

\section{INCLUSIVE GOVERNANCE}

Borth and Nicholson focus in on this question of public debate by arguing for a deliberative orientation when it comes to the inclusion of CDR into country level climate policy goals. They offer a number of recommendations, including expressing the intent for deliberation directly in Nationally Determined Contributions; embedding considerations of people in institutions responsible for shaping the roles that CDR will play; and ensuring correspondence between project level questions and country level targets. Lezaun proposes a framework for increasing local participation in the assessment of marine $\mathrm{CDR}$ in particular, to counter framings such as planetary scale geoengineering that obscure the local and site-specific nature of many marine CDR proposals. He argues that this must begin with expanding the range of actors and factors included in discussions, for example in marine spatial planning. Thinking about global inclusion, Healey et al. warn how CDR policies may be inequitable if they are seen to avoid or delay gross emission reductions, use natural resources at a scale that threatens food security, leave knowledge of CDR as a Global North monopoly, or leave the implications of CDR for development unexamined. The use of CDR, they argue, requires global agreement on reducing emissions and enhancing removals, equity in burden sharing, and an interdisciplinary effort led by individual jurisdictions to create CDR portfolios that are matched to local needs.

\section{REFORMING GOVERNANCE}

Turning to the current state of existing CDR governance, Schenuit et al. synthesize commonalities and differences in recent developments in CDR policy in eight OECD countries and the $\mathrm{EU}$, using an analytical framework that draws on the multilevel perspective of sociotechnical transitions. They propose a typology of three varieties of emerging CDR policymaking: incremental modification of existing national policy mixes; early integration of CDR policy that treats emission reductions and removals as fungible; and proactive CDR policy entrepreneurship with support for niche development. Fridahl et al. examine the extent to which existing international (UN), supranational (EU), and national (Swedish) climate policy instruments incentivize bioenergy with carbon capture and storage (BECCS). They find that no instruments create sufficient demand-pull to cover operational expenditure, economic instruments provide only partial technology-push support, and regulatory instruments provide only partial clarity on environmental safeguards and responsibilities. They conclude that the existing policy mix requires substantial reform if BECCS is to contribute to Sweden's or other EU Member States' climate policy targets.

The lack of demand-pull instruments in the EU is further explored by Rickels et al. They observe that despite the emissions cap in the EU Emissions Trading System (ETS) becoming net negative in one of the central EU-wide net zero scenarios, no mechanism allows for the inclusion of CDR credits. They conceptually discuss economic, legal, and political challenges surrounding the integration of CDR credits into the EU ETS. At the US State level, Sanchez et al. contemplate administrative changes to California's Low Carbon Fuel Standard to further stimulate commercialization of promising low carbon 
and carbon negative fuels. They propose embracing up-todate science regarding lifecycle greenhouse gas emissions; creating additional, targeted incentives through a volumetric technology carve-out or credit multiplier; and ensuring that the standard stimulates the best-performing fuels across a range of sustainability criteria. In terms of international reforms, Honegger et al. develop six functions which they argue are jointly needed for policy mixes to mobilize CDR in a way that is compatible with the Paris Agreement. These include clarity on the role for CDR; accelerating innovation for affordable and reliable CDR options; ensuring public participation in decision making on CDR; transitioning from piloting to scaled operations; ensuring robust monitoring, reporting, verification, and accounting; and preventing adverse impacts and maximizing co-benefits for sustainable development goals.

More generally, Carton et al. highlight that the obfuscation of emissions reductions by treating emissions and removals as equivalent is not the only problem of equivalence in CDR accounting. To ensure a just response to the climate crisis, they argue for the "undoing" of three additional problematic equivalences in carbon accounting: the equivalence of fossil and biotic forms of carbon; the equivalence of emissions and removals across different geographies; and the equivalence of present and near-term mitigation actions and those projected in the distant future.

\section{CREATING GOVERNANCE}

However, reforms can only go so far, and Zetterberg et al. offer five possible models for creating new incentives and financing for BECCS, using Sweden as an example. These include: government guarantees for purchasing BECCS outcomes; quota obligations on selected sectors; allowing BECCS credits to compensate for hard-to-abate emissions within the EU ETS; using private entities for voluntary compensation; and other states acting as buyers of BECCS outcomes to meet their mitigation targets. They conclude that successful implementation of BECCS will require a combination of several of these, implemented sequentially. Also looking at BECCS, Klement et al. argue that pulp and paper mills have potential for commercial roll-out of BECCS, and they seek to find business-driven ways of incentivising BECCS within this industry. By projecting the costs and negative emissions related to BECCS from the pulp mill to typical consumer products, they show how BECCS can substantially reduce their carbon footprint, while only marginally increasing their cost.

\section{GOVERNANCE SYSTEMS}

Turning to the wider institutional contexts in which CDR governance is mediated, Hansson et al. analyse BECCSrelated expert review comments and author responses on the Intergovernmental Panel on Climate Change (IPCC) Special Report on $1.5^{\circ} \mathrm{C}$. They show that boundary work at the sciencepolicy interface acts to deflect fundamental critiques of BECCS, particularly regarding the way in which it is presented as a viable technology at a grand scale. This, they argue, threatens to undermine the IPCC's ambition of opening up its scientific work to include more diversity in the process of drafting reports, and potentially also influence the governance of CDR. Palmer and Carton then turn to examine how BECCS is evolving into "BECCUS"-bioenergy with carbon utilization and storageseeing this as a "fix" for fossil fuel capitalism predicated on reconfiguring the relationship between climate change and energy use, and not simply as an attempt to make BECCS more economically viable. They call for CDR governance to adjudicate between conflicting ideas about the role of intensive energy use in future global sustainable development pathways. Finally, considering the wider systems in which CDR governance will emerge, Hall and Davis argue that critical social science should name and analyse the structural features of capitalism and their relation to CDR and its governance. They offer three principles to assist with this: that CDR is likely to emerge within capitalism, which is crisis prone, growth dependent, and market expanding; that there are different varieties of capitalism and this will affect the feasibility of different CDR policies; and that capitalism is ideologically and culturally maintained.

\section{SUMMARY}

The articles in this Research Topic contribute critical knowledge on the framing, inclusiveness, reformation, creation, and systems of emerging CDR governance. These contributions will be invaluable for government, industry and civil society stakeholders seeking to understand, reform and expand governance for CDR. They also represent an important resource for researchers seeking to build upon the nascent questions raised herein. What framings are still missing from the CDR governance debate? How can we implement and evaluate more geographically inclusive CDR governance? How do implemented reforms and new CDR governance creations perform in practice, and what other decision-making processes and policy frameworks might still be needed? How does CDR governance impact and interact with other systems and mechanisms for climate change mitigation and adaptation, and with non-climate goals? And finally, how can institutions and economic systems be reformed to account for alternative perspectives and to embed principles of just governance?

\section{AUTHOR CONTRIBUTIONS}

$\mathrm{RB}$ wrote the editorial with input from all authors to edit and improve the final text of the article.

\section{ACKNOWLEDGMENTS}

RB acknowledges funding from the University of Manchester's Presidential Fellowship scheme and the Natural Environment Research Council under grant NE/V013106/1 ( $\mathrm{CO}_{2}$ Removal $\mathrm{Hub}, \mathrm{CO}_{2} \mathrm{RE}$ ). MF acknowledges funding from the Swedish Research Council Formas (grant 2019-01993 and 2019-01973) and the Swedish Energy Agency (grant 46222-1 and 51569-1). 
EC acknowledges funding from the Engineering and Physical Sciences Research Council under grants EP/S029575/1 (UK Energy Research Center) and EP/V011960/1 (Delivering Net

\section{REFERENCES}

Bellamy, R. (2018): Incentivize negative emissions responsibly. Na. Energy 3, 532-534. doi: 10.1038/s41560-018-0156-6

Bellamy, R., Fridahl, M., Lezaun, J., Palmer, J., Rodriguez, E., Lefvert, A., et al. (2021): Incentivising bioenergy with carbon capture and storage (BECCS) responsibly: Comparing stakeholder policy preferences in the United Kingdom and Sweden. Environ. Sci. Policy 116, 47-55. doi: 10.1016/j.envsci.2020.09.022

Bellamy, R., and Geden, O. (2019): Govern $\mathrm{CO}_{2}$ removal from the ground up. Nat. Geosci. 12, 874-876. doi: 10.1038/s41561-019-0475-7

Cox, E., and Edwards, N. (2019): Beyond carbon pricing: policy levers for negative emissions technologies. Clim. Policy 19, 1144-1156. doi: 10.1080/14693062.2019.1634509

Fridahl, M., Hansson, A., and Haikola, S. (2020): Towards indicators for a negative emissions climate stabilisation index: problems and prospects. Climate 8, 75. doi: 10.3390/cli806 0075
Zero project), and from the Leverhulme Trust under grant RC-2015-029. JP acknowledges funding from the University of Bristol's Vice-Chancellor's Fellowships scheme.

Conflict of Interest: The authors declare that the research was conducted in the absence of any commercial or financial relationships that could be construed as a potential conflict of interest.

Publisher's Note: All claims expressed in this article are solely those of the authors and do not necessarily represent those of their affiliated organizations, or those of the publisher, the editors and the reviewers. Any product that may be evaluated in this article, or claim that may be made by its manufacturer, is not guaranteed or endorsed by the publisher.

Copyright (C) 2021 Bellamy, Geden, Fridahl, Cox and Palmer. This is an open-access article distributed under the terms of the Creative Commons Attribution License (CC $B Y)$. The use, distribution or reproduction in other forums is permitted, provided the original author(s) and the copyright owner(s) are credited and that the original publication in this journal is cited, in accordance with accepted academic practice. No use, distribution or reproduction is permitted which does not comply with these terms. 